\title{
OVICIDAL ACTION OF INSECTOACARICIDE DRUGS SENTRY HOME, NEOSTOMAZAN 1:200 MANUFACURED BY CEVA, NEOSTOMAZAN 1:200 MANUFACURED BY PRODUCT AND EXTRAZOL M ON FLEAS CTENOCEPHALIDES SPP. EGGS
}

\author{
Olga Yasynovska \\ Department of Veterinary-Sanitary Examination, Microbiology, \\ and Zoohygiene and Food Safety and Quality \\ Sumy National Agrarian University \\ 160 Herasyma Kondratieva str., Sumy, Ukraine, 40021 \\ yasinovskaya1989@gmail.com
}

\begin{abstract}
The aim of the research. To compare the ovicidal efficiency of insectoacaricides of different composition and manufacturers on flea eggs (Ctenocephalides spp.) for treatemnt of the premises where animals live.

Materials and methods of the research. The study was conducted on the basis of the clinic of veterinary medicine «Vetservice» Sumy, laboratory «Veterinary Pharmacy» and «Innovative technologies and safety and quality of livestock products» of Sumy National Agrarian University. The ovicidal effect of insectoacaricides on flea eggs of Ctenocephalides spp. was studied. Ctenocephalides spp. eggs were selected from the pet bedding on which the animal spended most of its time, namely the cats. The studied material was selected with a cosmetic brush. Ctenocephalides spp. eggs were placed into a Petri dish of 10 eggs per each dish. The test material was introduced with a dental probe. There were 4 test dishes, which were treated with insectoacaricides (each test dish was treated with a separate drug) and 1 control dish with no treatment. Microscopy was conducted under a light microscope with magnification X8 of each egg, with following treatment of each egg with insectoacaricides. Monitoring was conducted in 24 , 48 and 72 hours after treatment.

Results. Research has shown that drugs which demonstrated $100 \%$ ovicidal effectiveness were Sentry Home (pyriproxyfen $-0.02 \%$, permethrin $-0.2 \%$, n-Octyl Bicyclohepten $-1.0 \%$ ) in 24 hours and Neostomazan (CEVA) (transmix - 5.0 g, tetramethrin $-0.5 \mathrm{~g}$ ) in 72 hours.

Conclusions. Insectoacaricide drug Sentry Home (pyriproxyfen - $0.02 \%$, permethrin $-0.2 \%$, n-Octyl Bicyclohepten - $1.0 \%$ ), used for the treatment of the premises where the animals live, showed the most pronounced ovicidal effect in 24 hours.

Keywords: Ovicidal action, insectoacaricide drug, Ctenocephalides spp., effectiveness of ovicidal action.
\end{abstract}

DOI: $10.21303 / 2504-5679.2021 .001692$

\section{Introduction}

The main object of the study was the ovicidal effect of the insectoacaricide drugs Sentry Home, Neostomazan 1:200, manufactured by CEVA, Neostomazan 1:200, manufactured by PRODUCT, Extrazol M on flea eggs (Stenocephalides spp.), namely the number of living eggs after treatment with insectoacaricides, to determine the effectiveness of the treatment of the premises when using insectoacaricides in practice.

Fleas are temporary parasites. The development of insects occurs with a complete transformation. The life cycle of fleas is a complete transformation, lasting from 14 to 140 days, depending on temperature and humidity. They live in animal fur or nests. Females after fertilization lay up to 450-2500 eggs in the cracks of buildings, trees, land, debris and sometimes on animal skin, where they fall into places of sleep or rest of the animal.

Eggs are small, oval with blunt poles, slightly transparent, milky white or pearl color, size $0.5 \times 0.3 \mathrm{~mm}$, can be larger than $0.5-1 \mathrm{~mm}$. Eggs are not sticky, so they roll from the animal into the environment. White larvae develop from eggs on the $2^{\text {nd }}-14^{\text {th }}$ day, but the development of larvae from eggs can take up to 60 days and it depends on the ambient temperature. The larvae are wormlike, $4 \mathrm{~mm}$ long, similar in appearance to the larvae of flies, the body segments have sparse but long hairs. They have a rodent-type mouthparts. Flea larvae have a fairly large head and 13 joints. The smallest larvae that have just hatched from an egg have a small egg tooth on the tip - a hard 
growth that helps them break through the egg shell. The tooth falls off along with the chitinous shell during the first moult. Flea larvae can starve long enough - up to 3-4 weeks. At the same time they do not develop and do not grow, but do not fall into anabiosis. The larvae have a so-called phototaxis - wherever they are, they try to get into the least illuminated place. Although the eyes of flea larvae are almost undeveloped, they feel light well and try to hide from a lighted place. Indoors, flea larvae survive at the base of carpets, cracks in wooden floors. The development of cat fleas depends on temperature and humidity. In the southern regions, the flea development cycle lasts up to 3 weeks, in the central and northern, with a cool climate - up to 2 years. Fleas live 1-4 years. Still, there are data on the life of fleas up to 5 years $[1,2]$.

Fleas are common everywhere. These insects cause the most damage to dogs and cats. They also attack people. Distributed in places where animals are kept in unsanitary conditions, in large groups. Places for favorable development in the room are pet bedding, thick carpets, baseboards and dirty floors. Potentially favorable places for development outside buildings are moist soil and shade. At very high temperatures, flea larvae dry out - at low humidity it occurs at $34-36{ }^{\circ} \mathrm{C}$. At high humidity (up to $90 \%$ ) larvae survive this temperature well. Excess water has a detrimental effect on the larvae. Under optimal conditions - at a temperature of about $23{ }^{\circ} \mathrm{C}$ and a humidity of $60 \%$ flea larvae develop in about three weeks. A significant number of fleas are observed in summer and autumn. Cat fleas cannot survive for long periods of time at low temperatures. The flea population is rare in pets in the winter months, but reinvasion usually occurs in spring and summer. They can be mechanical and biological vectors of pathogens. Flea saliva is toxic to animals and humans and causes allergic dermatitis [3, 4].

Parasitizing on many animals (rats, gophers, marmots), fleas are carriers of many zooanthroponotic diseases (plague, tularemia, myxomatosis, typhus) [5, 6].

Fleas parasite on the bodies of small pets. It is the second most common cause of dermatological diseases. Up to $80 \%$ of all allergic dermatitis in animals is due to fleas [7, 8].

The general population of fleas in different sources is different. Iatusevych A. I. points out that about 1,000 species of fleas have been registered, 30 of which parasitize humans and domestic animals, rodents [9, 10]. Zakhvatkin Iu. A. also counts about 1,000 species of fleas, of which 250 species are located at the territory of CIS [11, 12]. According to Dykyi I. L., there are up to 1,400 species of fleas from the order Siphonaptera in the world fauna. Of these, 500 species belonging to 50 genera were found in the CIS $[13,14]$. Vashchenok V. S. accounts more than 1800 species $[15,16]$, while Balashov Iu. S. and Pavlovych S. A. - 2000 fleas species, a quarter of which lives in the CIS territory $[17,18]$. Kuliieva Kh. F. and Donato Traversa indicate that more than 2,500 species and subspecies of fleas are known, of which 500 are registered in the CIS countries [19, 20].

Ierokhina O. M., Iatusevych A. I., Akbaiev M. Sh., Galat V. F., Abuladze K. I., Vodianov A. A., Lutsuk S. N., Tolokonnikov V. P. distinguish 3 genera of fleas that have veterinary significance: Ctenocephalides canis (in dogs), Ctenocephalides felis (in cats), Pulex irritans (in human) which belongs to Siphonaptera order [1, 4].

The disease caused by fleas of the Ctenocephalides genus has several names. First variant is according to the name of the order Siphonaptera - siphonapterosis [6]. The second one is Aphaniptera - aphanipterosis [11], which are synonymous names. There is also the name of the disease by the genus Ctenocephalides - ctenocephalidosis [1].

Data on the ovicidal efficacy of insectoacaricide drugs have been insufficiently studied. The aim was to investigate and compare the ovicidal efficacy of insectoacaricides: Sentry Home (pyriproxyfen $-0.02 \%$, permethrin $-0.2 \%$, n-Octyl Bicyclohepten $-1.0 \%$ ), manufactured in the USA; Neostomazan 1:200 (transmix $-5.0 \mathrm{~g}$, tetramethrin $-0.5 \mathrm{~g}$ ), manufactured by CEVA, France; Neostomazan 1:200 (transmix - $5.0 \mathrm{~g}$, tetramethrin - 0.5 g), manufactured by PRODUCT, Ukraine; Extrazol M (esbiothrin $-0.17 \%$, tetramethrin $-0.038 \%$, deltamethrin $-0.02 \%$ ), manufactured in Ukraine for the complex destruction of parasites since the first stage of their development [5, 17].

\section{Materials and methods of the research}

The study was carried out on the basis of the veterinary clinic «Vetservis» in Sumy from 1.03.2020 to 6.03.2020. The analyzed material was taken in an apartment where two cats lived. 
It was taken from a bedding of $100 \times 120 \mathrm{~cm}$ in size used for cats' sleeping. Approximately 150 eggs of Ctenocephalides spp. were collected. The selected material was divided into 6 Petri dishes and represented by 5 study groups and 1 control group.

The study was performed at a temperature of $21{ }^{\circ} \mathrm{C}$ and a humidity of $85 \%$. Temperature and humidity were measured with a psychrometric hygrometer VIT-1. The dishes were not covered. Humidity and temperature in the room were natural. There were created the same conditions that would have been in the treatment of the room in practice (the most natural conditions for the development of Ctenocephalides spp. eggs).

The studied drugs were divided into groups according to the active substances (Table 1).

Ten Ctenocephalides spp. eggs were placed in every dish.

Petri 1 - Sentry Home (pyriproxyfen - $0.02 \%$, permethrin - $0.2 \%$, n-Octyl Bicyclohepten $-1.0 \%$ ), manufactured in the USA.

Petri 2 - Neostomazan 1:200 (transmix - 5.0 g, tetramethrin - 0.5 g), manufactured by CEVA, France.

Petri 3 - Neostomazan 1:200 (transmix - 5.0 g, tetramethrin - $0.5 \mathrm{~g}$ ), manufactured by PRODUCT, Ukraine.

Petri 4 - Extrazol M (esbiothrin $-0.17 \%$, tetramethrin $-0.038 \%$, deltamethrin $-0.02 \%$ ), manufactured in Ukraine.

Petri 5 - The control group (flea eggs of Ctenocephalides spp. were placed in a control dish which was not processed by anything).

Flea eggs (Ctenocephalides spp.) were introduced into Petri dishes using a dental probe, after circling the wells with a laboratory pencil in a Petri dish. There were 10 wells in each dish. The experiment lasted 5 days.

The following changes in the processed material were evaluated:

1. The shell condition.

1.1. Deformation.

1.1.1. Complete.

1.1.2. Almost complete.

1.1.3. Average.

1.1.4. Partially.

1.1.5. No deformation observed.

2. Visualization of the larva.

3. Motor activity of the larva.

4. Hatched larvae.

5. Motor activity of hatched larvae.

The condition of the shell, namely the deformation, was assessed by the correct shape of the egg (eggs were small, oval with obtuse poles, slightly transparent, milky white or pearl color, size $0.5 \times 0.3 \mathrm{~mm}$, could be larger than $0.5-1 \mathrm{~mm}$ ). That is why the deformation of the shell was evaluated for it (the wall is smooth, without depressions - no deformation; there are depressions on the wall of the egg more than 10-20\% - partial, 30-50\% - medium, 60-70\% - almost complete, more $80 \%$ - full deformation). The image of the oval divided into 10 parts was superimposed on the image for this purpose.

The larva in the egg was visualized under a light microscope at magnification X4 or X8 and detected the presence of the larva under the egg shell and its motor activity.

The effectiveness of ovicidal action of drugs was determined by the difference between the number of viable eggs of Ctenocephalides Felis in the control and experimental group (the motor activity of the larva in the egg shell and the motor activity of the hatched larva were found) attributed to their number in the control and expressed as a percentage:

$$
E O A=\frac{E c-E e}{E c} \cdot 100,
$$

where $E O A$ - effectiveness of ovicidal action; $E c$ - the number of live eggs in the control group; $E e$ - the number of live eggs in the experimental group. 


\section{Results}

3. 1. The results of ovicidal action of the insectoacaricide drug Sentry Home (pyriproxyfen $-0.02 \%$, permethrin - $0.2 \%$, n-Octyl Bicyclohepten - $1.0 \%$ ) manufactured in the USA

Before treatment: The complete deformation was not found in any egg. There was a slightly deformed lower pole in two eggs. This is due to the fact that such a condition of an egg occurs before hatching from the larva. This fact was proved during the study of the biology of Ctenocephalides spp. egg development and which was found in no literary source. All eight eggs had a smooth surface and were oval in shape. Eight eggs had a transparent shell, and two eggs, which were in the hatching stage, had a slightly compacted shell. The larva was visualized in all ten eggs and motor activity of the larva was also observed in all eggs of fleas Ctenocephalides spp.

Twenty-four hours after treatment with insectoacaricide drug Sentry Home the following results were obtained. The complete deformation of the shell was found in 24 hours after treatment with insectoacaricide Sentry Home in $100 \%$ of the test material. It was also determined that the transparency of the shell in $100 \%$ of the test material was reduced, the larva was visualized in all eggs as well as the motor activity of the larva was absent in $100 \%$ and the shape of all eggs was completely changed in $100 \%$. Hatched larvae are absent. The result of ovicidal action after 24 hours:

$$
E O A=\frac{10-0}{0} \cdot 100=100 \%
$$

3. 2. The results of ovicidal action of the insectoacaricide drug Neostomazan 1:200 (transmix $-5.0 \mathrm{~g}$, tetramethrin $-0.5 \mathrm{~g}$ ) manufactured by CEVA, France

Before treatment: complete deformation was not found in any egg. The lower pole was slightly deformed in two eggs. This is due to the fact that this condition of the egg occurs before hatching from the larva, which we proved during the study of the biology of egg development Ctenocephalides spp. and which was found in no literary source. All eight eggs had a smooth surface and were oval in shape. All studied eggs of fleas Ctenocephalides Felis had a transparent shell. The larva was visualized in all ten eggs and motor activity of the larva was also observed in all flea eggs.

In 24 and 48 hours after treatment with insectoacarisede drug Neostomazan (CEVA) 1:200: complete deformation of the shell was in $40 \%$ of the treated material, average deformation of the shell - in $20 \%$, partial - in $40 \%$. The shell transparency was partially changed in $90 \%$ of the studied material; in $10 \%$ it remained unchanged. The larva was visualized in $100 \%$ of the studied material. The motor activity of the larva was recorded in $50 \%$ of the studied eggs and in $50 \%$ it was absent. The shape of Ctenocephalides spp eggs remained unchanged in $20 \%$, in $40 \%$ it was partially changed and in $40 \%$ it was completely changed. Hatched larvae were absent.

$$
E O A=\frac{10-5}{10} \cdot 100=50 \% \text {. }
$$

In 72 hours after treatment with insectoacarisede drug Neostomazan (CEVA) 1:200: Complete deformation of the egg shell was in $80 \%$ of the studied eggs, average - in $10 \%$ and partial also in $10 \%$. The transparency of the shell was changed in $100 \%$ of the test material. The larva was visualized in $100 \%$ of the examined eggs. The motor activity of the larva was absent in $100 \%$ of the studied objects. The shape of Ctenocephalides Felis eggs remained unchanged in $10 \%$ of processed eggs, partially changed - in $30 \%$, completely changed - in $60 \%$. Hatched larvae were absent.

$$
E O A=\frac{10-0}{10} \cdot 100=100 \%
$$

3. 3. The results of ovicidal action of the insectoacaricide drug Neostomazan 1:200 (transmix - 5.0 g, tetramethrin - 0.5 g), manufactured by PRODUCT, Ukraine

Before treatment: complete deformation was not found in any egg. All ten eggs had a smooth surface and were oval in shape. $60 \%$ of the examined Ctenocephalides spp. eggs had a transparent shell, $40 \%$ had a darker color, which can be explained by the stage of egg development. The larva was visualized in all ten eggs and motor activity of the larva was also observed in all eggs of Ctenocephalides spp. 
In 24 and 48 hours after treatment with insectoacarisede drug Neostomazan (PRODUCT) 1:200: Complete deformation of the egg shell was observed in $40 \%$ of the treated material, average deformation of the shell - in $20 \%$, partial - in $40 \%$. The transparency of the shell was completely preserved in $20 \%$ of the studied material, in $80 \%$ there was a partial change in the transparency of the shell. The larva was visualized in $100 \%$ of the studied material. The motor activity of the larva was preserved in $60 \%$ of processed eggs and in $40 \%$ it was absent. The shape of the eggs remained unchanged in $30 \%$ of the studied material, was partially changed in $30 \%$, completely changed in $40 \%$. Hatched larvae were absent.

$$
E O A=\frac{10-6}{10} \cdot 100=40 \% .
$$

In 72 hours after treatment with insectoacarisede drug Neostomazan (PRODUCT) 1:200: complete deformation of the egg shell was observed in $60 \%$ of the treated material, average deformation of the shell - in $20 \%$ and partial - in $20 \%$ of the studied material. The transparency of the shell was partially changed in $100 \%$ of the treated material. The larva was visualized in $100 \%$ of the processed material. The motor activity of the larva was preserved in $40 \%$ of eggs and was absent in $60 \%$. The shape of the eggs remained unchanged in $20 \%$, partially changed in $20 \%$, and completely changed in $60 \%$ of the processed material. Hatched larvae were absent.

$$
E O A=\frac{10-4}{10} \cdot 100=60 \% .
$$

3. 4. The results of ovicidal action of the insectoacaricide drug Extrazol M (esbiothrin $-0.17 \%$, tetramethrin $-0.038 \%$, deltamethrin $-0.02 \%$ ), manufactured in Ukraine

Before treatment: complete deformation was not found in any egg. All ten eggs had a smooth surface and were oval in shape. $50 \%$ of the examined Ctenocephalides spp.eggs had a transparent shell, $50 \%$ had a darker color, which can be explained by the stage of egg development. The larva was visualized in all ten eggs and motor activity of the larva was also observed in all eggs of fleas Ctenocephalides spp.

In 24 hours after treatment with insectoacarisede drug Extrazol M: complete deformation of the egg shell was in $20 \%$ of processed eggs, almost complete deformation of the shell - in $10 \%$, average deformation of the shell - in $20 \%$, partial - in $10 \%$. The shell deformation was absent in $40 \%$ of the studied material. The transparency of the shell was partially changed in $100 \%$ of processed eggs. Visualization of the larva in the egg shell was observed in $100 \%$ of the test material. Motor activity of the larva was observed in $60 \%$ of treated eggs. It was absent in $40 \%$ of the treated eggs. The shape of the eggs was partially changed in $10 \%$ of the studied material, completely the shape of the eggs changed in $40 \%$, remained unchanged in $50 \%$ of the processed eggs. Hatched larvae were absent.

$$
E O A=\frac{10-6}{10} \cdot 100=40 \% .
$$

In 48 hours after treatment with insectoacarisede drug Extrazol M: The shell was destroyed in $20 \%$ of processed eggs. Complete shell deformation was noticed in $40 \%$ of the studied material, partial shell deformation - in $30 \%$ and no shell deformation - in $10 \%$ of eggs. $20 \%$ of the processed eggs hatched, the same ones in which the shell was destroyed, but the larvae were dead. There were 8 eggs left ( $80 \%$ of the test material). The transparency of the shell was partially changed in $80 \%$ of the studied material. The larva was visualized in the egg shell in $80 \%$ of the test material. Motor activity of the larva was observed in $20 \%$ of treated eggs, in $80 \%$ it was absent. The shape of the eggs was partially changed in $20 \%$, completely changed - in $40 \%$, remained unchanged - in $20 \%$.

$$
E O A=\frac{10-2}{10} \cdot 100=80 \%
$$

In 72 hours after treatment with insectoacarisede drug Extrazol M: The destroyed shell was observed in $30 \%$ of the processed material. Complete deformation was noticed in $30 \%$ of treated 
eggs, almost complete - in $10 \%$, average deformation of the shell - in $20 \%$, partial deformation in $10 \%$. Another larva hatched, but it was dead and the total number of hatched larvae was $3(30 \%$ dead) within 72 hours after treatment. $70 \%$ of the tested eggs remained. The transparency of the shell was partially changed in $70 \%$ of the test material. The larva was visualized in $70 \%$ of the studied material. The motor activity of the larva was in $10 \%$ of processed eggs and in $60 \%$ it was absent. The shape of the eggs was partially changed in $20 \%$, unchanged - in $10 \%$, completely changed - in $40 \%$ of the studied material.

$$
E O A=\frac{10-9}{10} \cdot 100=90 \% .
$$

\section{5. Discussion of research results}

As a result of the study of the ovicidal efficacy of insectoacaricide drugs revealed ovicidal efficacy of insectoacaricide drugs based on pyrethroids and synergists of insectoacaricidal action of pyrethroids, pyrethrins and carbamates. The study makes it possible to choose the most effective insectoacaricide drug for the treatment of the premises in which the animals live (Table 1).

Table 1

Ovicidal effectiveness of insect acaricides

\begin{tabular}{|c|c|c|c|}
\hline The drug name & 24 hours & 48 hours & 72 hours \\
\hline Sentry Home (pyriproxyfen $-0.02 \%$, permethrin $-0.2 \%$, n-Octyl Bicyclohepten $-1.0 \%$ ) & $100 \%$ & & \\
\hline Neostomazan (CEVA) (transmix - $5.0 \mathrm{~g}$, tetramethrin $-0.5 \mathrm{~g})$ & $50 \%$ & $50 \%$ & $100 \%$ \\
\hline Neostomazan (PRODUCT) (transmix - $5.0 \mathrm{~g}$, tetramethrin $-0.5 \mathrm{~g})$ & $40 \%$ & $40 \%$ & $60 \%$ \\
\hline Extrazol $M$ (deltamethrin $-0.02 \%$, esbiothrin $-0.17 \%$, tetramethrin $-0.038 \%)$ & $40 \%$ & $80 \%$ & $90 \%$ \\
\hline
\end{tabular}

Research has shown that drugs which demonstrated $100 \%$ ovicidal effectiveness were Sentry Home (pyriproxyfen - $0.02 \%$, permethrin - $0.2 \%$, n-Octyl Bicyclohepten $-1.0 \%$ ) in 24 hours and Neostomazan (CEVA) (transmix - $5.0 \mathrm{~g}$, tetramethrin $-0.5 \mathrm{~g}$ ) in 72 hours (Table 2).

It is possible to make a conclusion that ovicidal efficiency of two identical combinations of Neostomazan (CEVA), manufactured in France (transmix - $5.0 \mathrm{~g}$, tetramethrin $-0.5 \mathrm{~g}$ ) and Neostomazan (PRODUCT), manufactured in Ukraine (transmix - $5.0 \mathrm{~g}$, tetramethrin $-0.5 \mathrm{~g}$ ) was compared. According to the results of the research, the place of synthesis of the molecule and the drug production are of great importance for its effectiveness.

\section{Discussion}

Fleas are common everywhere. These insects cause the most damage to dogs and cats. Places for favorable development in the room are pet bedding, thick carpets, baseboards and dirty floors. Under optimal conditions at a temperature of about $23^{\circ} \mathrm{C}$ and humidity of $60 \%$ larvae develop in about three weeks $[3,4]$.

The conducted experiment makes it possible to destroy fleas effectively at the first stage of their development (at the egg stage).

It has been experimentally determined that the insecticide Sentry Home kills not only the adult representatives of Ctenocephalides spp. (as indicated in the instructions for use of the drug), but also $100 \%$ of eggs of parasites within 24 hours after just one treatment. Insectoacaricide drug Neostomazan (manufactured by CEVA, France) showed $10 \%$ better ovicidal efficiency than Neostomazan (manufactured by PRODUCT, Ukraine). It is needed to treat the room with both of these drugs at least 2 times. Therefore, the insectoacaricide drug Sentry Home can be recommended for effective treatment of the premises in order to destroy fleas in the first stage of their development (at the egg stage).

Research limitations. Limitation of the research was that the study was conducted under the laboratory conditions. The owners may not comply with all processing conditions during the treatment of the premises where the animals live. This, in turn, may cause poor treatment quality of the premises. 
Prospects for further research. It is planned to conduct industrial research of insecticides Sentry Home, Neostomazan (CEVA), Neostomazan (PRODUCT) in the conditions of real living of animals: homes, booths.

\section{Conclusions}

The study showed the maximum ovicidal efficacy of the insecticide Sentry Home (pyriproxyfen $-0.02 \%$, permethrin $-0.2 \%$, n-Octyl Bicyclohepten $-1.0 \%$ ) which gives $100 \%$ ovicidal efficacy after 24 hours.

Studies have shown that the insecticide Neostomazan (CEVA, manufactured in France) has a $10 \%$ better ovicidal efficacy than the insecticide Neostomazan (PRODUCT, manufactured in Ukraine).

\section{Conflicts of interest}

The authors declare that they have no conflicts of interest.

\section{References}

[1] McElroy, K. M., Blagburn, B. L., Breitschwerdt, E. B., Mead, P. S., McQuiston, J. H. (2010). Flea-associated zoonotic diseases of cats in the USA: bartonellosis, flea-borne rickettsioses, and plague. Trends in Parasitology, 26 (4), 197-204. doi: http:// doi.org/10.1016/j.pt.2010.01.001

[2] Bitam, I., Dittmar, K., Parola, P., Whiting, M. F., Raoult, D. (2010). Fleas and flea-borne diseases. International Journal of Infectious Diseases, 14 (8), e667-e676. doi: http://doi.org/10.1016/j.ijid.2009.11.011

[3] Dobler, G., Pfeffer, M. (2011). Fleas as parasites of the family Canidae. Parasites \& Vectors, 4 (1). doi: http://doi.org/10.1186/ 1756-3305-4-139

[4] Kernif, T., Chomel, B. B., Raoult, D., Aissi, M., Bitam, I., Doumandji, S.-E. (2010). Molecular Evidence of Bartonella Infection in Domestic Dogs from Algeria, North Africa, by Polymerase Chain Reaction (PCR). The American Journal of Tropical Medicine and Hygiene, 83 (2), 298-300. doi: http://doi.org/10.4269/ajtmh.2010.09-0052

[5] Fourie, J. J., Crafford, D., Horak, I. G., Stanneck, D. (2012). Prophylactic treatment of flea-infested cats with an imidacloprid/ flumethrin collar to forestall infection with Dipylidium caninum. Parasites \& Vectors, 5 (1), 151. doi: http://doi.org/10.1186/ 1756-3305-5-151

[6] Rust, M. (2017). The Biology and Ecology of Cat Fleas and Advancements in Their Pest Management: A Review. Insects, 8 (4), 118. doi: http://doi.org/10.3390/insects8040118

[7] Coles, T. B., Dryden, M. W. (2014). Insecticide/acaricide resistance in fleas and ticks infesting dogs and cats. Parasites \& Vectors, 7 (1), 8. doi: http://doi.org/10.1186/1756-3305-7-8

[8] Dryden, M. W., Payne, P. A., Smith, V., Berg, T. C., Lane, M. (2013). Efficacy of selamectin, spinosad, and spinosad/ milbemycin oxime against the KS1 Ctenocephalides felis flea strain infesting dogs. Parasites \& Vectors, 6 (1). doi: http:// doi.org/10.1186/1756-3305-6-80

[9] Dryden, M. W., Payne, P. A., Smith, V., Heaney, K., Sun, F. (2013). Efficacy of indoxacarb applied to cats against the adult cat flea, Ctenocephalides felis, flea eggs and adult flea emergence. Parasites \& Vectors, 6 (1). doi: http://doi.org/10.1186/ 1756-3305-6-126

[10] George, D. R., Finn, R. D., Graham, K. M., Sparagano, O. A. (2014). Present and future potential of plant-derived products to control arthropods of veterinary and medical significance. Parasites \& Vectors, 7 (1), 28. doi: http://doi.org/10.1186/ 1756-3305-7-28

[11] Olivry, T., DeBoer, D. J., Favrot, C., Jackson, H. A., Mueller, R. S. et. al. (2015). Treatment of canine atopic dermatitis: 2015 updated guidelines from the International Committee on Allergic Diseases of Animals (ICADA). BMC Veterinary Research, 11 (1). doi: http://doi.org/10.1186/s12917-015-0514-6

[12] Deziel, N. C., Colt, J. S., Kent, E. E., Gunier, R. B., Reynolds, P., Booth, B. et. al. (2015). Associations between self-reported pest treatments and pesticide concentrations in carpet dust. Environmental Health, 14 (1). doi: http://doi.org/10.1186/ s12940-015-0015-x

[13] Beugnet, F., Soll, M., Bouhsira, E., Franc, M. (2015). Sustained speed of kill and repellency of a novel combination of fipronil and permethrin against Ctenocephalides canis flea infestations in dogs. Parasites \& Vectors, 8 (1), 52. doi: http:// doi.org/10.1186/s13071-015-0680-1

[14] Hoffmann, S., Horak, I. G., Bennett, N. C., Lutermann, H. (2016). Evidence for interspecific interactions in the ectoparasite infracommunity of a wild mammal. Parasites \& Vectors, 9 (1). doi: http://doi.org/10.1186/s13071-016-1342-7 
[15] Halos, L., Fourie, J. J., Fankhauser, B., Beugnet, F. (2016). Knock-down and speed of kill of a combination of fipronil and permethrin for the prevention of Ctenocephalides felis flea infestation in dogs. Parasites \& Vectors, 9 (1). doi: http:// doi.org/10.1186/s13071-016-1345-4

[16] Dryden, M. W., Smith, V., Davis, W. L., Settje, T., Hostetler, J. (2016). Evaluation and comparison of a flumethrin-imidacloprid collar and repeated monthly treatments of fipronil/(s)-methoprene to control flea, Ctenocephalides f. felis, infestations on cats for eight months. Parasites \& Vectors, 9 (1). doi: http://doi.org/10.1186/s13071-016-1575-5

[17] Pfister, K., Armstrong, R. (2016). Systemically and cutaneously distributed ectoparasiticides: a review of the efficacy against ticks and fleas on dogs. Parasites \& Vectors, 9 (1). doi: http://doi.org/10.1186/s13071-016-1719-7

[18] Paarlberg, T., Winkle, J., Rumschlag, A. J., Young, L. M., Ryan, W. G., Snyder, D. E. (2017). Effectiveness and residual speed of flea kill of a novel spot on formulation of spinetoram (Cheristin ${ }^{\circledR}$ ) for cats. Parasites \& Vectors, 10 (1). doi: http:// doi.org/10.1186/s13071-017-1996-9

[19] Chatzis, M. K., Psemmas, D., Papadopoulos, E., Navarro, C., Saridomichelakis, M. N. (2017). A field trial of a fixed combination of permethrin and fipronil (Effitix $\left.{ }^{\circledR}\right)$ for the treatment and prevention of flea infestation in dogs living with sheep. Parasites \& Vectors, 10 (1). doi: http://doi.org/10.1186/s13071-017-2145-1

[20] Delcombel, R., Karembe, H., Nare, B., Burton, A., Liebenberg, J., Fourie, J., Varloud, M. (2017). Synergy between dinotefuran and fipronil against the cat flea (Ctenocephalides felis): improved onset of action and residual speed of kill in adult cats. Parasites \& Vectors, 10 (1). doi: http://doi.org/10.1186/s13071-017-2272-8

How to cite: Yasynovska, O. (2021). Ovicidal action of insectoacaricide drugs sentry home, Neostomazan 1:200 manufacured by CEVA, Neostomazan 1:200 manufacured by product and Extrazol M on fleas Ctenocephalides spp. eggs. EUREKA: Health Sciences, 2, 111-118. doi: http://doi.org/10.21303/2504-5679.2021.001692 